\begin{tabular}{c} 
Volume and Issues Obtainable at Center for Sustainability Research and Consultancy \\
Journal of Business and Social Review in Emerging Economies \\
ISSN: 2519-089X (E): 2519-0326 \\
Volume 6: Issue 2 June 2020 \\
JSRᄃ \\
Journal homepage: www.publishing.globalcsrc.org/jbsee \\
\hline
\end{tabular}

\title{
Investigation of Critical Factors for Successful ERP Implementation: An Exploratory Study
}

\author{
${ }^{1}$ Atif Ali Gill, ${ }^{2}$ Shaheera Amin, ${ }^{3}$ Ammara Saleem \\ ${ }^{1,2,3}$ Department of Business Administration. University of Sahiwal, Pakistan, \\ shaheeraamin@uosahiwal.edu.pk
}

\begin{tabular}{|c|c|}
\hline ARTICLE DETAILS & RACT \\
\hline $\begin{array}{l}\text { History } \\
\text { Revised format: May } 2020 \\
\text { Available Online: June } \\
2020\end{array}$ & $\begin{array}{l}\text { Enterprise Resource Planning (ERP) has become vital for any } \\
\text { organization to get a competitive advantage in today's world. } \\
\text { Financial organizations are improving their performance by } \\
\text { replacing old legacy systems with the latest integrated ERP software }\end{array}$ \\
\hline $\begin{array}{l}\text { Keywords } \\
\text { Enterprise resource } \\
\text { planning (ERP), } \\
\text { Contingency theory, Critical } \\
\text { Success, Factors (CSF), } \\
\text { Social cognitive theory } \\
(S C T) \text {. }\end{array}$ & $\begin{array}{l}\text { packages. This study purposed to identify the vital determinants of } \\
\text { ERP successful implementation in the banking sector. The data has } \\
\text { been collected from the thirteen largest well-known commercial } \\
\text { banks in Pakistan. This study is qualitative in nature and data has } \\
\text { been collected interviews from respondents. After analyzing through } \\
\text { thematic analysis, this study found the new theoretical model for } \\
\text { future empirical investigation. Researchers and Practitioners can use }\end{array}$ \\
\hline JEL Classification & tation of ERP in the \\
\hline
\end{tabular}

(C) 2020 The authors, under a Creative Commons Attribution-

NonCommercial 4.0

Corresponding author's email address: shaheeraamin@uosahiwal.edu.pk

Recommended citation: Gill A.A., Amin S., Saleem A. (2020). Investigation of Critical Factors for Successful ERP Implementation: An Exploratory Study. Journal of Business and Social Review in Emerging Economies, 6 (2), 565-575

\section{Introduction}

ERP is a comprehensive software package for organizations which integrates all enterprise processes (Ullah, Baharun, Nor, \& Yasir, 2018). ERP provides effective communication among all departments of the organization in real-time (Balasubramanian \& Selladurai, 2018). When stakeholders ask for information, then ERP systems accumulate data from the value chain and convert it into meaningful information which later enterprise uses for decision making (Rouhani \& Mehri, 2018). This aspect allows the enterprise to spotlight on beneficial activities (Nwankpa, 2018). By the use of ERP, an enterprise can upgrade its core activities to meet the industry standards (Rouhani \& Mehri, 2018). ERP implementation benefits can be achieved at numerous levels including management level, operations level, IT hardware level and organizational level (Xu, Ou, \& Fan, 2017). ERP is significant software for the progress of a firm (Queiroz, Tallon, Sharma, \& Coltman, 2018). 
Despite the numerous benefits of ERP system as mentioned above, still many organizations are failed to implement it successfully due to ERP system complexity and extensive procedure (Alraddadi, Champion, \& Lagna, 2018; Baskaran, 2018; Liao, Huang, \& Lin, 2018; Thomas, Mmereki, \& Boy, 2018). ERP installation also requires a lot of resources and finance to get the desired results. Many researchers suggested determinants of ERP implementation in multiple industrial sectors and critical factors have been identified in diverse contexts (Ahmed, Shaikh, \& Sarim, 2017; Ali, Hussin, Othman, Elzamly, \& Doheir, 2018; Baskaran, 2018). Some found the sociological factors and technological aspects (Xu et al., 2017). Few shed light on strategical and procedural facets (Schniederjans \& Yadav, 2013). While others look at the organizational and operational elements in ERP implementation (Xu et al., 2017). Some authors investigated the crucial factors to successfully deploy the ERP system regarding the content of organization volume, functions and suppliers (Heckmann, Steger, \& Dowling, 2016).

Moreover, financial sector always comprises high importance in the economy of any country. Similarly, banking industry is core element of financial sector to make progress. Banks in Pakistan are governed by State Bank which works as a regulatory authority. State Bank of Pakistan has advised all the banks, whether scheduled and non-scheduled banks to integrate all the functions so that centralized database can be arranged. Many banks implemented ERP by contacting the vendors, like Oracle, SAP, and Microsoft. These ERP systems cost billions to these banks including migration cost to shift from old legacy system to new ERP package. However, there is lack of formal research to find out the vital factors in the successful completion of the ERP project in this context. Hence, this exploratory study will bridge this gap to find out critical success factors in Success implementation of ERP software package in banks of Pakistan. Following research question has been derived through stated earlier:

RQ1: What are the critical success factors of ERP system successful implementation in the banking sector of Pakistan?

Further sections include the theoretical foundation of this study followed by methodology, findings, conceptual model and at the end discussion, limitations and future predictions have been illustrated.

\section{Theoretical Foundations}

An earlier form of Enterprise Resource Planning systems is known as manufacturing resource planning which was unable to prioritize the tasks efficiently which is a constraint for effective multitasking activities and it was developed for the manufacturing sector only (Abdullah, 2017). To overcome this issue closed-loop MRP systems were presented which contains scheduling techniques to perform certain tasks simultaneously (Schneider, Asprion, \& Grimberg, 2018). Later Enterprise Resource Planning systems were introduced which can estimate supply and inventory detail to meet future demand and to keep the business process integrated \& efficient in immense competition and rapidly changing the environment (Abdullah, 2017; Schneider et al., 2018; Wang, Gong, \& Wang, 2017).

However, risk factors are always involved in ERP implementation. Management primarily focused on the procedural as well as economic aspects of the execution of the ERP project rather non-technical matters (Schniederjans \& Yadav, 2013). Numerous studies have been performed to discover the reason for such failures.

Further, a successfully accomplished ERP system can give inspiring strategic, outfitted and informationrelated reimbursement to approving firms, contrarily an unsuccessful implementation can bring financial disaster to the organization. Most of the information about the breakdowns and achievements are based on manufacturing sector. However, ERP vendors are at the present steadily revolving their marketing places of interest on small as well as medium-sized manufacturers as well as the financial sector of developing countries.

Contingency theory describe the overall structure of organization depending the environment (Hung, 
Chang, Yen, Kang, \& Kuo, 2011). Contingency factors reflect the factors of environment which include both internal and external and play significant role to fit the environment for successful implementation of centralized integrated system. ERP requires change in business procedures and Management active involvement, user education, skills and training are important factors to ensure effective deployment of system. While social cognitive theory provided the individual behavior framework, i.e., self-efficacy and their impact on successful implementation of ERP system in organization.

Management involvement, supportive climate, staff readiness and education are contingent factors which harmonize the difficult procedure of ERP system implementation in organization. Previous studies illustrated certain contingent inter-organizational aspects which are vital from information system deployment while still in developing countries it required more in-depth investigation to explore these issues. Above literature postulate the following proposition:

P1: Inter-organizational factors influence successful implementation of ERP.

Characteristics of ERP system represent the technological aspects of contingent theory which impact the effectiveness of ERP implementation in organization. These technological factors include infrastructure of information technology in organization where ERP system is going to implement while it also represents the information technology knowledge and skills of employees who are the end user of ERP system, it may also include other factors like IT budgeting to meet the completion of ERP project implementation within the stipulated time. This all lead to the below mentioned proposition:

P2: Technology factors influence successful implementation of ERP.

The ability of individual to face a situation mainly depend upon his own willingness and effectiveness to handle the issue. Researcher mentioned the effectiveness of individual like self-efficacy which demonstrate the one's belief to perform any task. Individuals with high effectiveness expectations are more likely to succeed in a given task (Olivier \& Shapiro, 1993). Literature stated that successful implementation of information system is influenced by the induced level of individuals' performance which is purposed the below stated proposition:

P3: Individual factors influence successful implementation of ERP.

The bank is a financial intermediary aiming at accepting deposits, then channeling those deposits for lending activities. In Pakistan banking sector has evolved rapidly in last few years. Banks deal with many clients and give different types of services and if the clients are not satisfied with the services provided by the banks, then they will withdraw their deposits from banking industry which will affect the whole economy since banking industry plays a key role in the economy of a country. Banks key to business performance is to attract and establish a client market and would need to keep retain it through agreement. Technology plays a very vital role in increasing Customer satisfaction which includes efficient services and product novelty. It is necessary for the Banks to invest in core business improvements and Technology capabilities to attract more customers. As a customer of modern banks are very demanding and always want to get their work done in a short span of time. Due to the customer always has a shortage of time and always demand efficient services. To increase the efficiency of core banking services, banks need complete business process re-engineering and modernize the procedure from bottom to top, ERP system supports the financial sector to achieve this effect in their services by providing centralized database inventory and client-server environment.

\section{Methodology}

The inductive approach has been used in this study. Thirteen commercial banks which are using ERP system in Pakistan are selected for the sample. Respondents are IT Managers working at mid-level position in IT department of each bank. Purposive sampling technique has been used. For qualitative 
data, collection interviews are taken from respondents. Interview protocol has been established before taking interviews with the respondents.

\subsection{Thematic Analysis}

Thematic analysis is used in this study to understand any phenomenon by analyzing the diverse aspects of that phenomenon and gathering data from different ways. The thematic analysis provides an opportunity for the researcher to understand the worth of any problem more widely.

\subsection{Discourse Conversational Analysis}

Discourse and conversational analysis help to discover the pattern within the language than relate it with the context of the study. There are different types of discourse analysis. In this study conversational discourse analysis has been used to understand the professional documentation, interview material and provide the real picture of the problem as it depicts the experiences of the participants.

\section{Qualitative Data Analysis}

This section provides the details of interview transcription. Interviews were transcribed immediately after meeting with participants because it is still fresh in their memory. The shorthand expert who accompanied the researcher in each interview and helped to ensure the transcribed information is the same as what participants mentioned in the interview.

Thematic analysis was used to analyze the transcribed data in the present research. The thematic analysis provides rich details for identifying the essential factors that fulfil the objectives of this study. Braun and Clarke (2006) provided the six phases to perform the thematic analysis. These phases are not linear processes and the researcher could move back and forth the phases during the qualitative data analysis.

Phase 1: Becoming familiar with data

Braun and Clarke (2006) argued that thematic analysis should be initiated during data collection because the researcher is acquainted with data and more interactions enhance knowledge about patterns of data. While transcribing the next participant's data, the researcher may find something similar to the previous transcribed data and this confirms this idea and supports the researcher to become more familiar with the data. The researcher must read and reread data at this phase and get more acquainted with the data. In the present study, data were transcribed immediately after interviews (mostly same day). In this way, the researcher obtained detailed data and after conducting the 12th interview, the researcher reached the saturation point with no further need for more interviews.

Phase 2: Generating initial codes

Weston et al. (2001) mentioned that coding is not just a process of data analysis; it provides a strong relationship between the development of coding and the evolution of understanding a phenomenon. In the present research, the process involved generating codes from three different questions. The codes for the first research question are the different technological factors affecting the post-implementation success of ERP in an organization belonging to the manufacturing, services and retail industry in Pakistan. The codes for the second research question are the different organizational factors affecting the post-implementation success of ERP in an organization belonging to the manufacturing, services and retail industry in Pakistan, while the codes for the third question are the different environmental factors affecting the post-implementation success of ERP in an organization belonging to the manufacturing, services and retail industry in Pakistan. The codes were grouped according to the research question to 
ensure accuracy. Braun and Clarke (2006) emphasized generating maximum codes from data to avoid any loss of the essence of the data.

Phase 3: Searching for themes

This phase moves to the next level and different codes are sorted out and collated into potential themes (Braun \& Clarke, 2006). In the current study, there were three sets of codes and repeated codes or similar codes were collated in the relevant theme. This phase required an in-depth reading of codes as sometimes, the same concept might be told in another way by the participants of the present study, while some codes could not be extracted from the data. They had to be grasped after going through the description. If there were codes which were not suitable to any potential theme, then a miscellaneous theme was generated to put them under this theme to avoid any data loss; besides, the codes of the miscellaneous theme may fit into some relevant theme after carefully studying them (Braun \& Clarke, 2006). A summary statistic is calculated by software to analyze the significance of the theme as the codes evolved.

Phase 4: Reviewing the themes

This phase is essential to finalize the themes by carefully analyzing the codes gathered in each theme to find out whether or not these codes make any sense and provide a clear pattern (Braun \& Clarke, 2006). In the present study, the researcher did pragmatic validation by confirming from research participants and they agreed on the different TOE factors affecting the post-implementation success of ERP as stated by them and grouped into the suitable themes.

Phase 5: Defining and naming themes

After phase four, this phase is an ongoing process to scrutinize the specifics of each theme to provide a precise definition of each theme. This naming process of each theme was based on the codes and data provided by the participants instead of taking from past literature. However, due to the technical nature of the subject matter, themes were having technical names as mentioned by different researchers in their studies which also depicts the validity of data.

Phase 6: Producing the report

After finalizing the clearly defined themes, the last step is formalizing the report. Braun and Clarke (2006) stated the importance of providing sufficient evidence to support the themes. In the present study, the report of findings is presented in the next chapter. Quotes from participants are mentioned in the report to provide evidence of the themes formed and a clear picture to answer the three questions asked in the current study.

In the present study, Nvivo 12 software was employed for data analysis and certain queries were employed to generate results from the transcribed data. The coding query was most important query while conducting a thematic analysis of the current study. By using the coding query, it added textual data in inverted commas to give weight to participants' views which were provided as evidence of the themes in the present study (Braun \& Clarke, 2006). The matrix coding query was also used to display different themes on rows and participants on columns. 
Table 1

Qualitative participants' characteristics

\begin{tabular}{lcclcll}
\hline $\begin{array}{l}\text { Company/ } \\
\text { Participant } \\
\text { code }\end{array}$ & Gender & $\begin{array}{c}\text { Age } \\
\text { (years) }\end{array}$ & Education & $\begin{array}{c}\text { Experience } \\
\text { using ERP } \\
\text { (years) }\end{array}$ & $\begin{array}{l}\text { Management } \\
\text { position }\end{array}$ & $\begin{array}{l}\text { ERP } \\
\text { Software } \\
\text { Type }\end{array}$ \\
\hline A (P1) & Male & 33 & Master & 5 & Mid-level & $\begin{array}{l}\text { Oracle } \\
\text { B (P2) }\end{array}$ \\
Male & 45 & Graduation & 8 & Mid-level & SAP \\
C (P3) & Male & 39 & Master & 6 & Mid-level & SAP \\
D (P4) & Male & 38 & Master & 7 & Mid-level & Oracle \\
E (P5) & Male & 30 & Master & 4 & Mid-level & Oracle \\
F (P6) & Male & 35 & Graduation & 4 & Mid-level & Microsoft \\
G (P7) & Male & 32 & Graduation & 5 & Mid-level & SAP \\
H (P8) & Male & 45 & Master & 7 & Mid-level & SAP \\
I (P9) & Male & 31 & Graduation & 3 & Mid-level & SAP \\
J (P10) & Male & 40 & Master & 8 & Mid-level & Microsoft \\
K (P11) & Male & 40 & Graduation & 7 & Mid-level & Oracle \\
L (P12) & Male & 35 & Master & 5 & Mid-level & SAP \\
M (P13) & Male & 38 & Master & 3 & Mid-level & SAP \\
\hline
\end{tabular}

\section{Findings}

\subsection{Internal-Organization Factors}

Following figure 1 shows the internal organization success factors, which are explored through qualitative interviews include training and education, management commitment, management involvement, the incentive to employees and organizational policies. A major response was given by respondent 7 and respondent 1 .

Figure 1. Qualitative analysis results (Inter-Organization Factors)

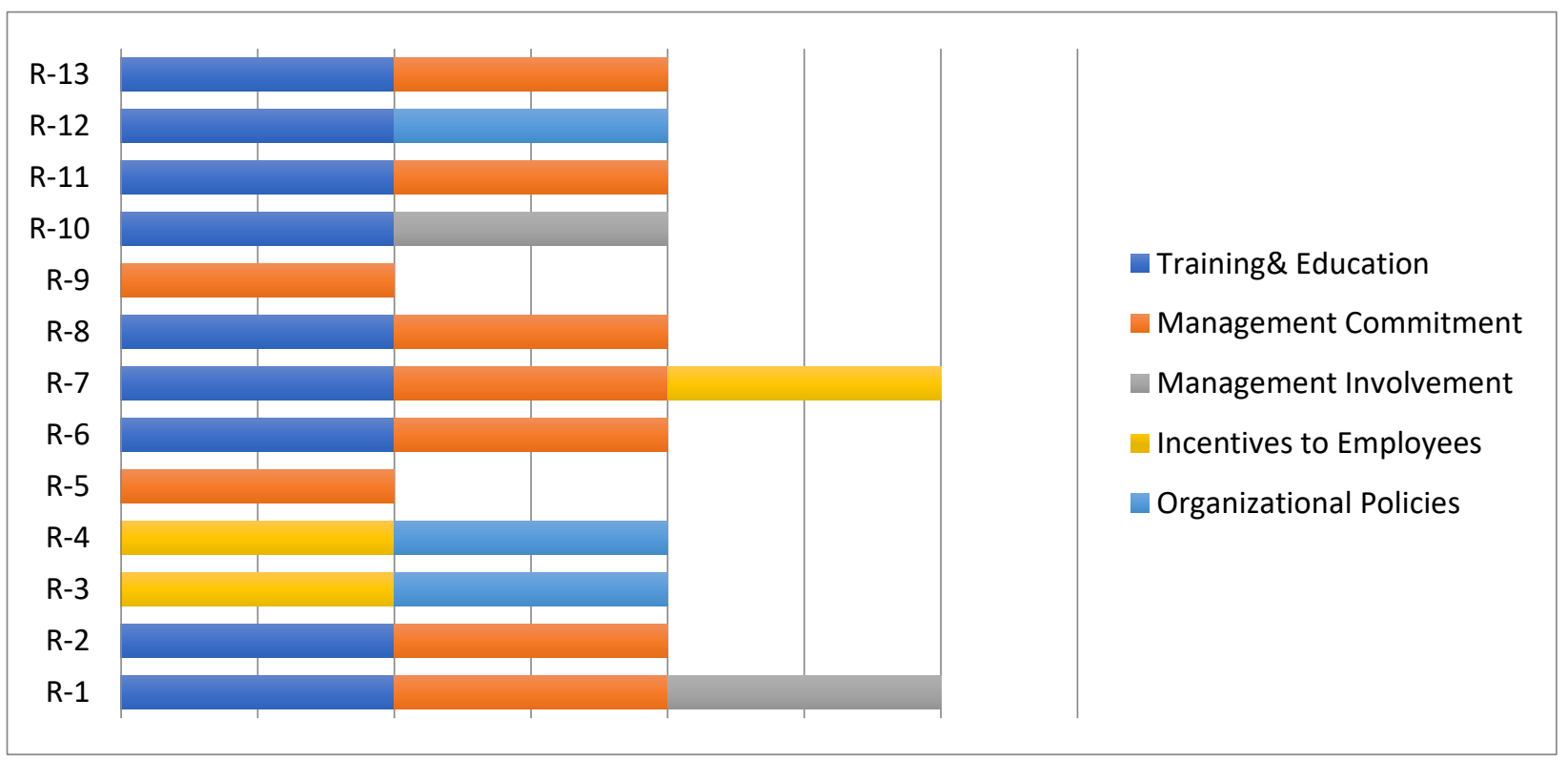




\subsection{Technological Factors}

Following figure 2 depicts the technological critical success factors explored through qualitative interviews analysis which are mentioned as IT budget, IT infrastructure and IT skills, Major responses from respondent 4 .

Figure 2. Qualitative analysis results (Technological Factors)

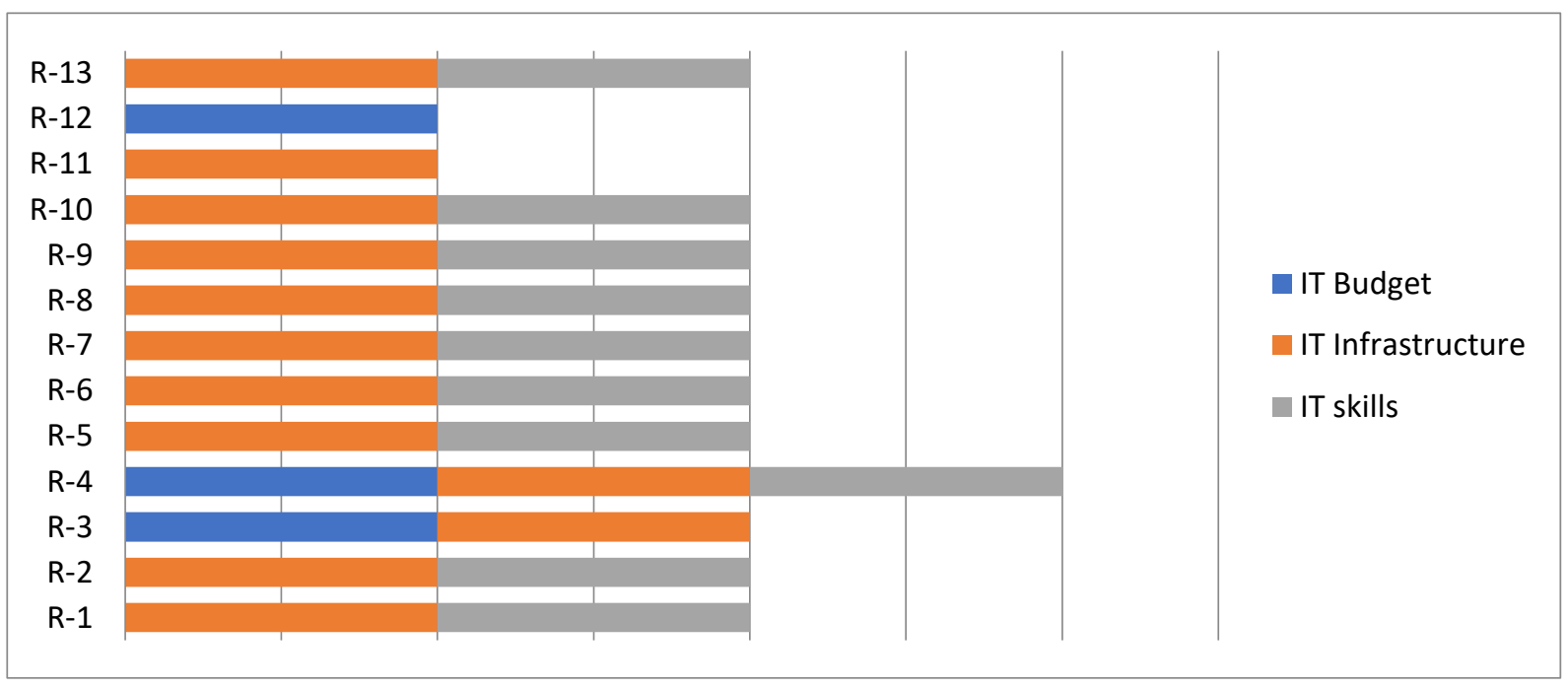

\subsection{Individual Critical Success Factors}

Following figure 3 demonstrates the individual critical success factors explored through qualitative interviews analysis that includes user involvement, self-efficacy, and learning capacity.

Figure 3. Qualitative analysis results (Individual Factors)

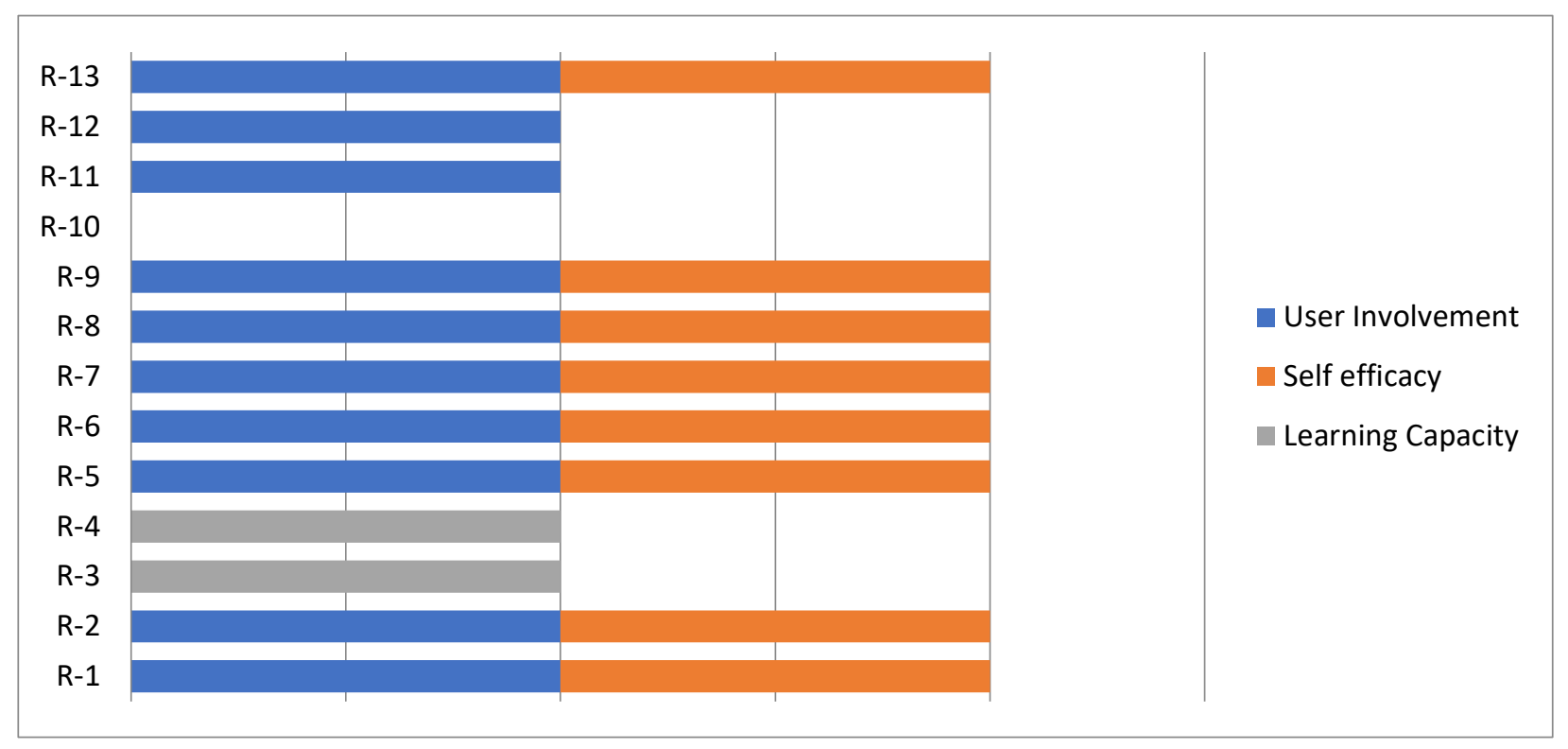


Nodes compared by number of items coded

\begin{tabular}{|c|c|c|c|c|c|c|}
\hline \multicolumn{3}{|c|}{ Internal organizational Factors } & \multicolumn{2}{|c|}{ Technological Factors } & \multicolumn{2}{|l|}{ Individual Factors } \\
\hline \multirow[t]{4}{*}{ Training and education } & \multirow[t]{4}{*}{ Management commitmer } & ncentives to Employe & \multirow[t]{4}{*}{ 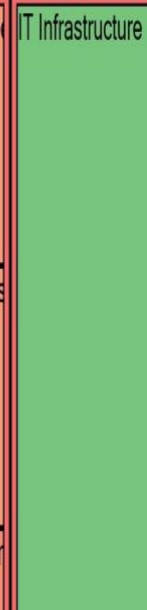 } & \multirow[t]{2}{*}{ TT skills } & \multirow[t]{4}{*}{ User involvement } & \multirow[t]{3}{*}{ Self efficacy } \\
\hline & & Organziational policies & & & & \\
\hline & & Management Involvem & & Thudget & & \\
\hline & & & & & & Learming Capacity \\
\hline
\end{tabular}

Figure 4. frequency query results

aaaaaa about also an arrange available aware back bank banking basic basically because budget capacity change commitment committed confidence confident department doing education efficacy employee employees enough equipment end every factors from going graduates hardware has he helpful how implement implementation implemented important incentives individual infrastructure internal involved involvement learn level main management more most necessary new old order organization organziation other people person policies proper properly results second secondly Self skills so software some sort

successful sufficient

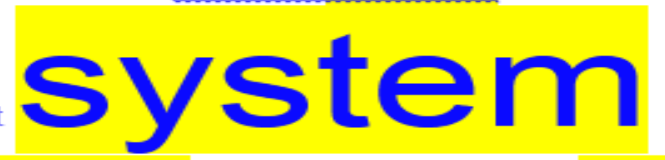
systems

technological technology them towards trained training two type up USe using vital We what which work working would yes young

Figure 5. word frequency query 
Conceptual Model derived from Qualitative Findings

\section{Critical Success Factors}

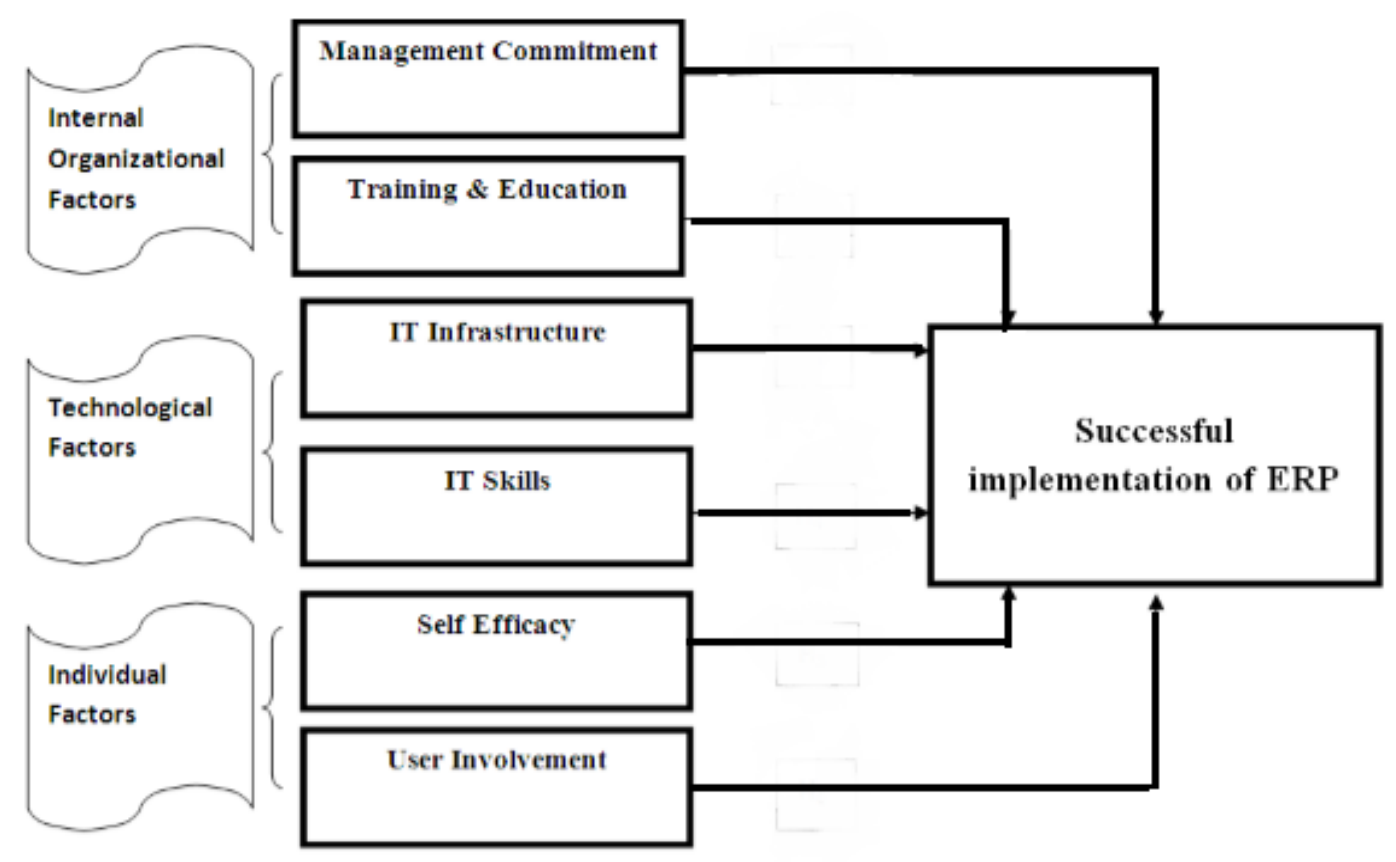

Figure 6. Conceptual Model

The conceptual model shown in figure 6 gets through qualitative data analysis as shown in figure $4 \& 5$. interviews taken from respondents and seven major factors identified which are most critical as per respondents of banking sector that include management commitment and Training and education in inter-organizational factors while in technological factors respondents mostly discussed about the IT infrastructure importance and IT skills necessity. As per individual factors, respondents are more concerned about self-efficacy and user involvement.

\section{Discussion and Implications}

Top management commitment is very important for the effectiveness of ERP implementation. Migrating from old legacy system to centralized ERP software package is a cumbersome process and due to complexity of procedures usually employees become fed up or thinking about losing their jobs, top management at that time play crucial role to boost the morale of employees and effective communication can remove any hindrance. Training \& Education is another critical factor for smooth implementation of ERP because end users are not technical especially in financial sector they expert in their specific work but not technical in IT related matters so proper training can increase the success ration of ERP because sometimes user interface and query generation methods are complex and technical in nature they require pre-training and guidance to employees. IT infrastructure is the backbone of ERP successful implementation due to comprehensive software package ERP needs more sophisticated IT resources, especially computers, Servers, internet media, bandwidth. IT infrastructure must be upgraded to consultant recommendations to ensure ERP success. IT skills to play the vital role of migrating data to ERP.

The organization must have a skilful team to ensure smooth ERP implementation to avoid any mishap after deployment, which may cause huge financial loss. Self-efficacy \& User involvement are very important throughout the procedure of ERP implementation in the organization because staff sometimes 
lose their attention and show lack of interest which should be guided not management and do certain activities to engage all staff through the migration or deployment process.

This study provides multiple implications for researchers and management by providing key determinants of successful ERP implementation which can use in another non-financial sector to validate the study. This study provides valuable insights to minimize the risk factor for ERP implementation in organizations.

\section{Limitations and Future Research Directions}

This study used the sample of the banking sector in Pakistan, while in future this research can be conducted in other non-financial sectors. In this research, cultural factors are not considered which few previous research reveal as critical factor so they can embrace in some future research to explore cultural factors which impact the successful implementation of ERP. This research can be enhanced by taking organization performance as the criterion construct to analyze the ERP implementation effects upon business growth.

\section{Refrences}

Abdullah, M. A. M. A. (2017). Evolution of Enterprise Resource Planning. Evolution, 1(11).

Ahmed, N., Shaikh, A. A., \& Sarim, M. (2017). Critical Success Factors Plays a Vital Role in ERP Implementation in Developing Countries: An Exploratory Study in Pakistan. International Journal Of Advanced Computer Science And Applications, 8(10), 21-29.

Ali, W., Hussin, B., Othman, M. F. B., Elzamly, A., \& Doheir, M. (2018). Identifying and Evaluating Critical Risks and Controls in The Implementation Of ERP Systems (Case Study In UAE).

Alraddadi, A., Champion, D., \& Lagna, A. (2018). The Role of Workarounds in Benefits Realization: Evidence from a Field Study in Saudi Arabia.

Balasubramanian, K., \& Selladurai, V. (2018). Contemporary ERP solution to Indian small and medium scale enterprises through constructive performance metrics. International Journal of Business Excellence, 15(4), 445-466.

Bandura, A. (1982). Self-efficacy mechanism in human agency. American Psychologist, 37(2), 122.

Baskaran, R. (2018). An Empirical Study on determining the critical success factors for the implementation of Hybrid Cloud ERP system in IT Organizations.

Braun, V., \& Clarke, V. (2006). Using thematic analysis in psychology. Qualitative Research in Psychology, 3(2), 77-101. https://doi.org/10.1191/1478088706qp063oa

Heckmann, N., Steger, T., \& Dowling, M. (2016). Organizational capacity for change, change experience, and change project performance. Journal of Business Research, 69(2), 777-784.

Hung, S.-Y., Chang, S.-I., Yen, D. C., Kang, T.-C., \& Kuo, C.-P. (2011). Successful implementation of collaborative product commerce: An organizational fit perspective. Decision Support Systems, 50(2), 501-510.

Liao, L.-M., Huang, C.-J., \& Lin, X.-Y. (2018). Applying Project Management Perspective for ERP Implementation: A Case Study. Proceedings of Engineering and Technology Innovation, 8, 4045.

Nwankpa, J. K. (2018). ERP Systems Benefit Realization and the Role of ERP-Enabled Application Integration. In Encyclopedia of Information Science and Technology, Fourth Edition (pp. 29532964). IGI Global.

Olivier, T. A., \& Shapiro, F. (1993). Self-efficacy and computers. Journal of Computer-Based Instruction, 20(3), 81-85. 
Queiroz, M., Tallon, P. P., Sharma, R., \& Coltman, T. (2018). The role of IT application orchestration capability in improving agility and performance. The Journal of Strategic Information Systems, 27(1), 4-21.

Rouhani, S., \& Mehri, M. (2018). Empowering benefits of ERP systems implementation: empirical study of industrial firms. Journal of Systems and Information Technology, 20(1), 54-72.

Schneider, B., Asprion, P. M., \& Grimberg, F. (2018). Interconnected Enterprise Systems- A Call for New Teaching Approaches. In International Conference on Computational Science (pp. 318331). Springer.

Schniederjans, D., \& Yadav, S. (2013). Successful ERP implementation: an integrative model. Business Process Management Journal, 19(2), 364-398.

Thomas, P. Y., Mmereki, R. N., \& Boy, R. L. (2018). Evaluation of an Academic and Student Administration System in its Post-Implementation Phase: A Case Study at the University of Botswana. International Journal of Enterprise Information Systems (IJEIS), 14(3), 79-90.

Ullah, A., Baharun, R. B., Nor, K., \& Yasir, M. (2018). Overview of Enterprise Resource Planning (ERP) System in Higher Education Institutions (HEIs). Advanced Science Letters, 24(6), 43994406.

Wang, H., Gong, Q., \& Wang, S. (2017). Information processing structures and decision making delays in MRP and JIT. International Journal of Production Economics, 188, 41-49.

Xu, W., Ou, P., \& Fan, W. (2017). Antecedents of ERP assimilation and its impact on ERP value: A TOE-based model and empirical test. Information Systems Frontiers, 19(1), 13-30. 